\title{
Degradation and osteogenic potential of a novel poly(lactic acid)/nano-sized $\beta$-tricalcium phosphate scaffold
}

This article was published in the following Dove Press journal:

International Journal of Nanomedicine

27 November 2012

Number of times this article has been viewed

\author{
Lu Cao ${ }^{1,2}$ \\ Ping-Guo Duan ${ }^{1,2}$ \\ Hui-Ren Wang ${ }^{1,2}$ \\ Xi-Lei Li ${ }^{1,2}$ \\ Feng-Lai Yuan ${ }^{3}$ \\ Zhong-Yong Fan ${ }^{4}$ \\ Su-Ming $\mathrm{Li}^{5}$ \\ Jian Dong ${ }^{1,2}$ \\ 'Department of Orthopedic \\ Surgery, Zhongshan Hospital, \\ Fudan University, Shanghai, China; \\ ${ }^{2}$ State Key Laboratory of Molecular \\ Engineering of Polymers, Fudan \\ University, Shanghai, China; \\ ${ }^{3}$ Affiliated Third Hospital of \\ Nantong University, Wuxi, Jiangsu, \\ China; ${ }^{4}$ Department of Materials \\ Science, Fudan University, Shanghai, \\ China; ${ }^{5}$ Max Mousseron Institute \\ on Biomolecules, Montpellier I \\ University, Montpellier, France
}

Correspondence: Jian Dong Department of Orthopedic Surgery, Zhongshan Hospital, Fudan University, 180 Fenglin Road, Shanghai 200032, China

Email dong.jian@zs-hospital.sh.cn

Su-Ming Li Max Mousseron, UMR CNRS 5247 Faculté de Pharmacie, Université Montpellier I

I5, Avenue Charles Flahault BP I449I, 34093 Montpellier Cedex 05, France

Email lisuming@hotmail.com

\begin{abstract}
The purpose of this study was to investigate the influence of nano-sized $\beta$-tricalcium phosphate ( $\beta$-TCP) on the biological performance of poly (lactic acid) (PLA) composite scaffolds by using in vitro degradation and an in vivo model of heterotopic bone formation. Nano-sized $\beta$-TCP (n $\beta$-TCP) was prepared with a wet grinding method from micro-sized $\beta$-TCP (m $\beta$-TCP), and composite scaffolds containing $0,10,30$, or $50 \mathrm{wt} \% \mathrm{n} \beta$-TCP or $30 \mathrm{wt} \% \mathrm{~m} \beta$-TCP were generated using a freeze-drying method. Degradation was assessed by monitoring changes in microstructure, $\mathrm{pH}$, weight, and compressive strength over a 26-week period of hydrolysis. Composite scaffolds were processed into blocks, and implanted into muscular pockets of rabbits after loading with recombinant human bone morphogenetic protein-2 (rhBMP-2). New bone formation was evaluated based on histological and immunohistochemical analysis 2, 4, and 8 weeks after implantation. The in vitro results indicated that the buffering effect of $n \beta-T C P$ was stronger than $\mathrm{m} \beta$-TCP, which was positively correlated with the content of $n \beta$-TCP. The in vivo findings demonstrated that $\mathrm{n} \beta$-TCP enhanced the osteoconductivity of the scaffolds. Although composite scaffolds containing 30\% n $\beta$-TCP exhibited similar osteoconductivity to $50 \% \mathrm{n} \beta$-TCP, they had better mechanical properties than the $50 \% \mathrm{n} \beta$-TCP scaffolds. This study supports the potential application of a composite scaffold containing $30 \% \mathrm{n} \beta$-TCP as a promising scaffold for bone regeneration.
\end{abstract}

Keywords: poly (lactic acid), $\beta$-tricalcium phosphate, biodegradation, porous scaffold, bone regeneration

\section{Introduction}

Scaffolds and growth factors are considered as key components for bone regeneration. ${ }^{1}$ Ideally scaffolds should be combined with cells and growth factors capable of osteogenesis. ${ }^{2}$ The biomimetic scaffold design aims at providing structural support as a temporary matrix for cell proliferation and extracellular matrix deposition until the bone tissue is restored/regenerated, and is then eventually resorbed, leaving only the newly formed living tissue and the fully healed lesion. ${ }^{3} \beta$-Tricalcium phosphate $(\beta$-TCP) has been widely used as a scaffold for bone repair due to its degradation behavior and similar $\mathrm{Ca} / \mathrm{P}$ ratio to hydroxyapatite. ${ }^{4,5}$ However, the application of $\beta$-TCP is limited in non-load bearing areas because of its brittle mechanical property. Poly (lactic acid) (PLA) and its copolymers have a long history of safe clinical use including suture, plates, and screws in orthopedic surgeries. Although PLA can also be designed as a scaffold with controlled mechanical properties, too many acidic degradation products of PLA can cause asepsis inflammation which will damage the microenvironment of bone healing. In addition, PLA lacks osteoconductivity. ${ }^{6}$ 
Recently, extensive research has been undertaken geared toward PLA/ $\beta$-TCP scaffold composites, in which the addition of $\beta$-TCP into the PLA scaffold should not only regulate its degradation properties, but also improve bioactivity and biological behavior. ${ }^{7}$ However, to the authors' knowledge, existing studies on PLA/ $\beta$-TCP scaffold composites were mainly focused on pore size, porosity, and mechanical behavior, and little attention has been paid to the influence of particle size of $\beta$-TCP on the biological performance of PLA/ $\beta$-TCP scaffolds for bone regeneration. Micro-sized particles would decrease the strength and ductility of the composite material. ${ }^{8}$ In addition, nano-sized $\beta$-TCP (n $\beta$-TCP) allows for the achievement of improved mechanical properties and tunable degradability compared to micro-sized powders. ${ }^{9}$ Furthermore, the interaction of osteoblasts with the nanosized surfaces of biomaterials is critical for keeping the body from rejecting implants, ${ }^{10}$ and it is beneficial for the adhesion, proliferation, and differentiation of osteoblasts on nano-sized rough surfaces of PLA. ${ }^{11,12}$

In the present study, we investigated the influence of $\mathrm{n} \beta$-TCP on the degradation behavior of PLA/n $\beta$-TCP composite scaffolds in phosphate-buffered saline (PBS) solution, and we also evaluated the biological performance of scaffolds by monitoring heterotopic bone formation after rhBMP-2incorporation. ${ }^{13}$ We found that both the particle size and the content of $\beta$-TCP could lead to differences in degradation and osteoconductive properties of PLA/n $\beta$-TCP porous scaffolds.

\section{Materials and methods Materials}

Micro-sized $\beta$-TCP (m $\beta$-TCP) was purchased from Beta Whitlockite Plasma Biotal (Tideswell, UK); the particle size distribution of $\beta$-TCP granules was $75-100 \mu \mathrm{m}$. Poly-L/DLlactide 70/30 was obtained from Purac Biochem BV (Gronichem, Netherlands). rhBMP-2 was purchased from Rebone Biomaterials Co, Ltd (Shanghai, China). Rabbit anti-osteocalcin (OCN) antibody was obtained from Abcam Inc (Cambridge, UK).

Ten-week-old New Zealand White rabbits weighing 2.2-2.7 kg were provided by the Laboratory Animal Center of Zhongshan Hospital, Fudan University. All the experimental procedures involving animals were approved by the Institutional Animal Care and Use Committee of Shanghai Fudan University, China.

\section{Preparation of $n \beta-T C P$ and PLA $/ \beta$-TCP composite scaffolds}

$\mathrm{n} \beta$-TCP was prepared using a wet grinding method. A mixture of $\mathrm{m} \beta$-TCP and diethylene glycol $(1: 1.5 \mathrm{w} / \mathrm{w})$ was milled with zirconia beads at 1,800 rev/minute for 12 hours in a high-speed ball grinder. $\mathrm{n} \beta$-TCP powder was obtained after replacing diethylene glycol with acetone.

A PLA solution of $1.5 \mathrm{wt} \%$ concentration was prepared by dissolving PLA in 1,4-dioxane as previously described. ${ }^{14}$ Then, $\beta$-TCP powder was added to the PLA solution. The compositions of the various composites are listed in Table 1. The solution was placed into custom-made Teflon molds (11 $\mathrm{mm}$ in diameter and $22 \mathrm{~mm}$ in height) and frozen at $-30^{\circ} \mathrm{C}$ for 24 hours before freeze-drying for 24 hours. Pure PLA scaffolds were fabricated under the same conditions. After removal of the molds, the scaffolds were stored at room temperature and under vacuum for at least 48 hours before sterilization with gamma irradiation at $25 \mathrm{kGy}$.

\section{Characterization of $n \beta$-TCP particles}

\section{X-ray diffraction}

$\mathrm{X}$-ray diffraction spectrometry was obtained using an XD-3A powder diffractometer (D/Max r-B; Rigaku Corporation, Tokyo, Japan). A $\mathrm{Cu} \mathrm{K} \alpha$ radiation at $40 \mathrm{kV}$ and $100 \mathrm{~mA}$ was used. Diffractograms were obtained from $2 \theta=3^{\circ}$ to $50^{\circ}$ with an increment of $0.02^{\circ}$, at a scanning speed of $4^{\circ}$ minute $(2 \theta)$.

\section{Particle size}

The average size, size distribution, and polydispersity index were determined by dynamic light scattering using a Zetasizer Nano series Nano-ZS (Malvern, UK). Measurements were performed at $633 \mathrm{~nm}$ with a constant angle of $90^{\circ}$ at $25^{\circ} \mathrm{C}$ after samples were appropriately diluted in ethanol and the mean value was obtained from triplicate samples.

\section{Transmission electron microscopy (TEM)}

The morphology of $\beta$-TCP nanoparticles was observed using a transmission electron microscope (H-7000; Hitachi, Ltd, Tokyo, Japan). A drop of sample solution (2 mg/mL) was placed onto a 300-mesh copper grid coated with carbon. After 2 minutes, the grid was tapped with filter paper to remove

Table I PLA/ $\beta$-TCP composite scaffold

\begin{tabular}{llll}
\hline Group & PLA (wt\%) & $\mathbf{m} \beta$-TCP $(w t \%)$ & $\mathbf{n} \beta-T C P(w t \%)$ \\
\hline PLA & 100 & 0 & 0 \\
PLA/10 n $\beta-T C P$ & 90 & 0 & 10 \\
PLA/30 m $\beta-T C P$ & 70 & 30 & 0 \\
PLA/30 n $\beta-T C P$ & 70 & 0 & 30 \\
PLA/50 n $\beta-T C P$ & 50 & 0 & 50 \\
\hline
\end{tabular}

Abbreviations: PLA, poly (lactic acid); $n \beta-T C P$, nano-sized $\beta$-tricalcium phosphate; m $\beta$-TCP, micro-sized $\beta$-tricalcium phosphate. 
surface water, followed by air drying. The grid was dried at room temperature and then observed by TEM.

\section{In vitro study}

Before degradation, all the porous scaffolds were pre-wetted with PBS under $\mathrm{pH} 7.4$ to ensure permeation through the scaffolds. ${ }^{15}$

Scanning electron microscopy (SEM; TS 5136MM; TESCAN, Brno, Czech Republic) was employed to characterize the internal and external morphologies of the scaffolds every 4 weeks. Testing samples with thickness of 2-3 mm were cut from the scaffolds using a blade, sputter-coated with gold, and observed with SEM. The scaffold porosity was measured by modified liquid displacement with absolute ethanol according to the previously published method; ${ }^{16}$ the pore sizes were evaluated by SEM. The $\mathrm{pH}$ of PBS was measured with a $\mathrm{pH}$-meter and replaced with fresh PBS every week. The mass changes were determined every 2 weeks, using the equation: $\operatorname{loss} \%=\left(\mathrm{W}_{\mathrm{r}}-\mathrm{W}_{0}\right) / \mathrm{W}_{0} \times 100$, where $\mathrm{W}_{0}$ was the original weight and $\mathrm{W}_{\mathrm{r}}$ was the dried weight of the porous scaffolds. A compressive strength testing machine (Model 1121; Instron Limited, Norwood, MA) was employed to evaluate the compressive properties of the dried scaffolds at $23^{\circ} \mathrm{C}$. Cylindrical scaffolds $(11 \mathrm{~mm}$ in diameter and $22 \mathrm{~mm}$ in height) were employed as testing samples. The measurements were run at $1.0 \mathrm{~mm} /$ minute.

\section{In vivo study}

\section{Study design and surgical procedure}

Thirty rabbits were divided into five groups based on the different implanted scaffolds. All implanted scaffolds had a similar size; blocks of $5 \mathrm{~mm} \times 5 \mathrm{~mm} \times 3 \mathrm{~mm}$ were treated with $20 \mu \mathrm{L}$ of rhBMP-2 (containing $4 \mu \mathrm{g}$ rhBMP-2) via microliter syringe before implantation. ${ }^{17}$ The rabbits were anesthetized with an intravenous injection of $3 \%$ ketamine $(1 \mathrm{~mL} / \mathrm{kg}$ ) and operated on under sterile conditions. Four $2 \mathrm{~cm}$ skin incisions were made on both sides of the spine, and an rhBMP-2-loaded block was inserted into each of the four muscular pockets before the muscle and skin were sutured separately. The embedded samples were harvested at 2, 4, and 8 weeks after implantation (from 10 rabbits every time) for histological examination.

\section{Histologic analysis}

All of the harvested samples were fixed in 4\% formalin in PBS and demineralized in $12.5 \%$ ethylene diamine tetraacetic acid solution. The samples were then embedded in paraffin, sectioned at $5 \mu \mathrm{m}$, and processed for hematoxylin and eosin staining. For morphometric analysis, five sequential sections per implant were selected for investigation under low magnification, allowing for coverage of the entire implant. Two independent observers evaluated all slides to identify the type of bone tissue or scaffolds and blood vessels using a Leica-Qwin 3.2 Image Analysis System (Leitz DMRD, Leica Microsystems, Inc, Bannockburn, IL). The extent of bone formation was indicated by the percentage of the bone tissue area, and an average value was calculated for each implant. Data were then averaged across all implants within each group.

\section{Immunohistochemical analysis}

Paraffin-embedded sections were deparaffinized in 100\% xylene for 10 minutes, and then hydrated with $100 \%$ ethanol for 5 minutes, $95 \%$ for 3 minutes, $80 \%$ for 3 minutes, and $70 \%$ for 3 minutes. After washing in distilled water, the sections were trypsin digested for 8 minutes for antigen retrieval, then washed three times in PBS. Afterward, the slides were incubated with $3 \%$ hydrogen peroxide for 10 minutes and washed three times in PBS. Then, the slides were incubated with primary antibodies for OCN for 1 hour in a humid chamber at $37^{\circ} \mathrm{C}$. After washing in PBS, the slides were incubated with secondary antibody conjugated with horseradish peroxidase for 30 minutes at $37^{\circ} \mathrm{C}$. Finally, the slides were incubated with $3,3^{\prime}$ diaminobenzidene chromogen and counterstained with hematoxylin for 1 minute.

The slides were examined for color change under a light microscope (Olympus BX-61; Olympus Corporation, Tokyo, Japan). The scoring of OCN was carried out by two independent pathologists according to the proportion of cells with positive nuclear staining (negative, none; weak, $\leq 10 \%$; moderate, $10 \%-50 \%$; strong, $>50 \%$ ).

\section{Statistical analysis}

All data are presented as mean \pm standard deviation (SD). Analysis of variance (ANOVA) was used to analyze the percentage of bone formation in each group. Statistical significance was defined as $P<0.05$.

\section{Results}

\section{Characterization of $n \beta-T C P$}

Figure 1 shows the X-ray diffraction patterns of the $\mathrm{m} \beta$-TCP and as-prepared $n \beta$-TCP powder. It revealed that both $\mathrm{m} \beta$-TCP and n $\beta$-TCP were composed of highly crystalline powder and no second phase other than $\beta$-TCP was detected. 


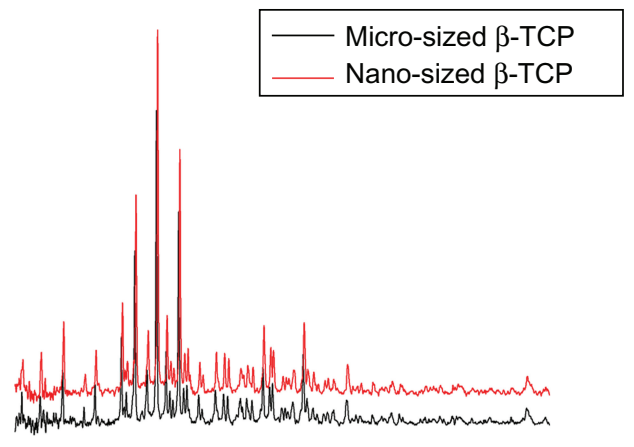

\begin{tabular}{cccccc}
\hline & 20 & 40 & 60 & 80 & 100 \\
& & Diffraction angle/20 & $\left({ }^{\circ}\right)$ & &
\end{tabular}

Figure I X-ray diffraction patterns of micro-sized $\beta$-TCP particles and as prepared nano-sized $\beta$-TCP particles.

Abbreviation: $\beta$-TCP, $\beta$-tricalcium phosphate.

The morphology of as-prepared n $\beta$-TCP nanoparticles was determined by TEM. Various irregular shapes were observed, with a size range of $20-160 \mathrm{~nm}$ (Figure 2A and B). On the other hand, as-prepared $\mathrm{n} \beta$-TCP exhibited a mean hydrodynamic diameter of $125 \mathrm{~nm}$ with a unimodal size distribution as estimated from dynamic light scattering (Figure 2C).

\section{In vitro degradation of scaffolds} Changes of pore morphology and porosity

The pore morphology appeared to be rather uniform in all of the original scaffolds. The pore morphology over time is shown in Figure 3. Pore walls of pure PLA scaffold had more smooth surfaces compared to those composite scaffolds with various ratios of $\beta$-TCP. For the first 8 weeks, no significant morphological changes were observed for any of the five groups. After 26 weeks of degradation, the number of pores decreased, some pore walls disappeared, and bigger pores were formed. The average pore size and porosity decreased in the order of PLA/50 n $\beta$-TCP, PLA/30 n $\beta$-TCP, and PLA/10 $\mathrm{n} \beta$-TCP. Additionally, PLA $/ 30 \mathrm{n} \beta$-TCP exhibited larger pore size and porosity than PLA/30 $\mathrm{m} \beta$-TCP.

Figure 4 shows the porosity changes of the different composite scaffolds. Prior to degradation, no significant differences were noted among the five groups, implying that the $\mathrm{n} \beta$-TCP ratio did not significantly affect the scaffold porosity. After 4 weeks, the scaffold porosity decreased to a minimum in all groups. Afterwards, the porosity increased over the remaining degradation period. The porosity of PLA $/ 50$ $n \beta$-TCP scaffolds increased faster than PLA/10 n $\beta$-TCP, PLA/30 n $\beta$-TCP, or PLA/50 n $\beta$-TCP scaffolds beyond 7 weeks. No significant differences in porosity changes were observed between PLA/30 n $\beta$-TCP and PLA/30 m $\beta$-TCP scaffolds over the 26 -week degradation period.

\section{Change of mass, compressive strength, and PBS pH}

Figure 5 demonstrates that all the scaffolds lost weight slowly during the initial stage. Weight loss of PLA/30 n $\beta$-TCP scaffolds was significantly faster than PLA/ $30 \mathrm{~m} \beta$-TCP scaffolds beyond 10 weeks. Weight loss of PLA/50 n $\beta$-TCP scaffolds was significantly faster than PLA/10 n $\beta$-TCP or PLA/30 $\mathrm{n} \beta$-TCP scaffolds beyond 5 weeks.

A constant decrease of compressive strength was observed over the 26-week degradation period, and the ratio of $\mathrm{n} \beta$-TCP significantly affected the initial compressive strength of the scaffolds (Figure 6). The compressive strength of PLA/30 $\mathrm{n} \beta$-TCP scaffolds remained higher than 1.0 MPa after 16 weeks. No significant differences in compressive strength were observed between the PLA/30 $\mathrm{n} \beta$-TCP and PLA/30 $\mathrm{m} \beta$-TCP scaffolds over the whole degradation period.

Figure 7 illustrates the $\mathrm{pH}$ change of PBS solution over time. None of the groups showed significant $\mathrm{pH}$ changes until
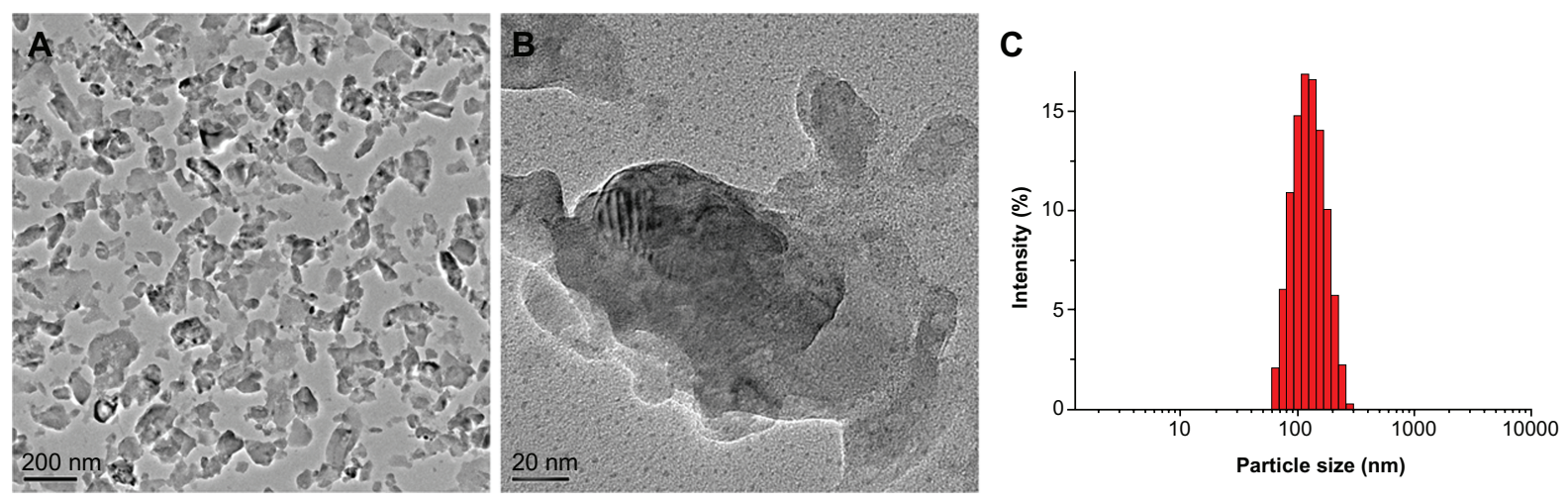

Figure 2 TEM images of dried particles $(\mathbf{A}$ and $\mathbf{B})$ and size distribution of nano-sized $\beta$-TCP particles (C). Abbreviations: TEM, transmission electron microscopy; $\beta$-TCP, $\beta$-tricalcium phosphate. 


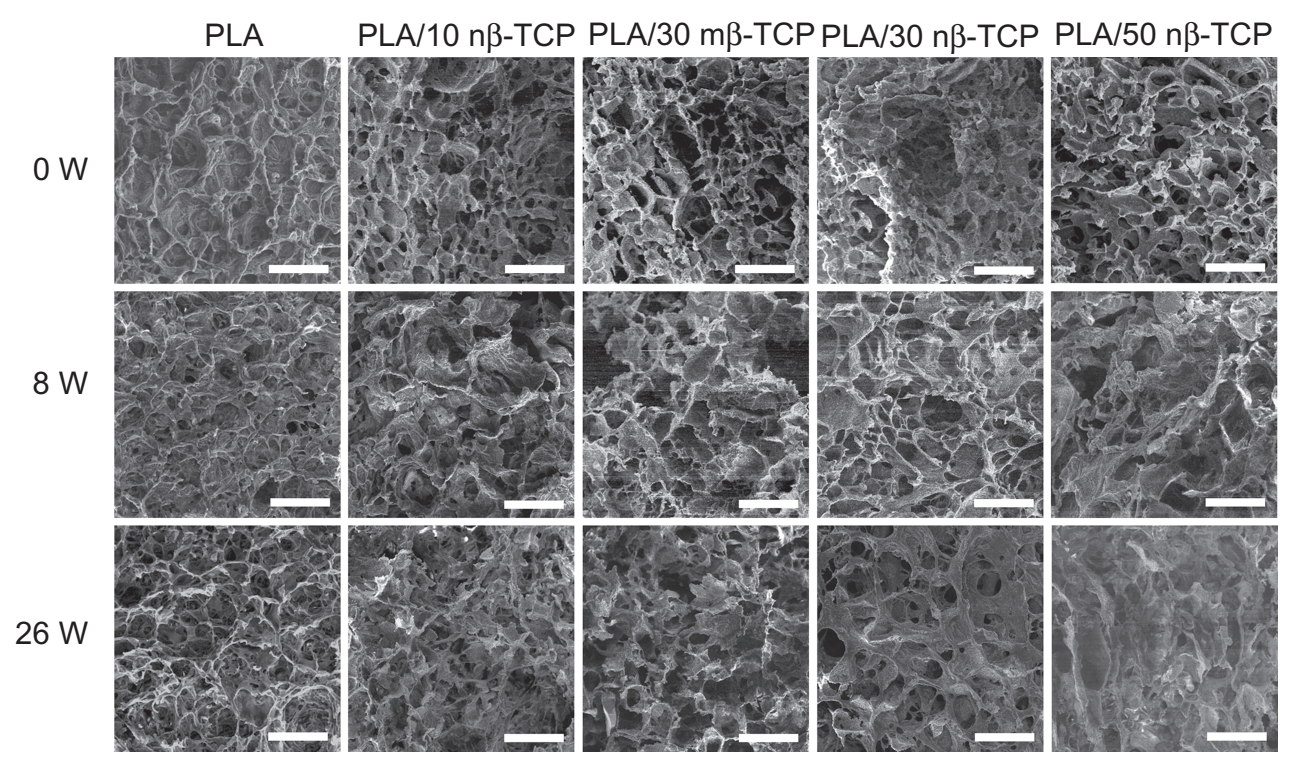

Figure 3 SEM micrographs of the pores on the external surface of five composite scaffolds at 0,8 , and 26 weeks: pure PLA, PLA/I0 n $\beta$-TCP, PLA/30 m $\beta$-TCP, PLA/30 $\mathrm{n} \beta-\mathrm{TCP}$, and PLA/50 n $\beta$-TCP scaffold.

Note: Scale bars: $300 \mu \mathrm{m}$.

Abbreviations: SEM, scanning electron microscopy; PLA, poly (lactic acid); $n \beta$-TCP, nano-sized $\beta$-tricalcium phosphate; m $\beta$-TCP, micro-sized $\beta$-tricalcium phosphate; W, weeks.

week 4 with a $\mathrm{pH}$ value between $7.33-7.39$. The $\mathrm{pH}$ of each group decreased between weeks 4 and 9. PLA/30 n $\beta$-TCP and PLA/50 $\mathrm{n} \beta$-TCP $\mathrm{pH}$ normalized in a range of 7.06-7.32 throughout the experiment, while PLA/30 $\mathrm{m} \beta-\mathrm{TCP}$ and PLA/10 $\mathrm{n} \beta$-TCP scaffolds reached their lowest $\mathrm{pH}$ at week 9 .

\section{In vivo study}

\section{Histological analysis}

All rabbits showed undisturbed wound healing without any clinical signs of inflammation over the implanted porous scaffolds.

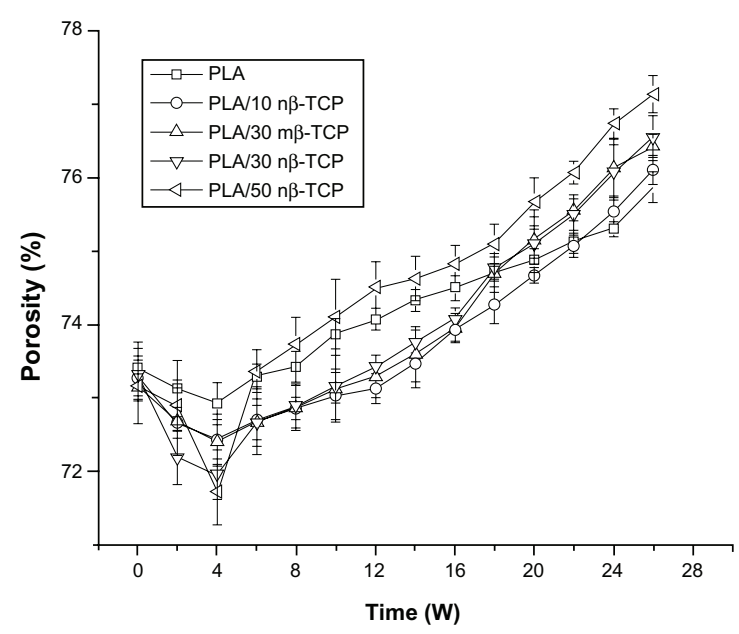

Figure 4 Porosity changes of five composite scaffolds over a 26-week period of hydrolysis.

Abbreviations: PLA, poly (lactic acid); $\mathrm{n} \beta$-TCP, nano-sized $\beta$-tricalcium phosphate; $\mathrm{m} \beta$-TCP, micro-sized $\beta$-tricalcium phosphate; $W$, weeks.
Two weeks after implantation of the rhBMP-2-loaded porous scaffolds, only a small quantity of fibrous tissue was observed either at the periphery or in the pores of the scaffolds from all groups. At week 4, more mature neo-bone and blood vessels were observed in PLA/30 m $\beta$-TCP, PLA/30 $n \beta$-TCP, and PLA/50 n $\beta$-TCP scaffolds than pure PLA and PLA/10 n $\beta$-TCP scaffolds (Figure 8). At week 8, the bone forming area in PLA/30 n $\beta$-TCP was $32.4 \% \pm 1.6 \%$, which was significantly higher than those of PLA/30 m $\beta$-TCP $(24.3 \% \pm 0.5 \%)$, PLA $/ 10 \mathrm{n} \beta-\mathrm{TCP}(21.3 \% \pm 1.2 \%)$, and PLA $(9.2 \% \pm 1.1 \%)(P<0.05)$. No significant difference with

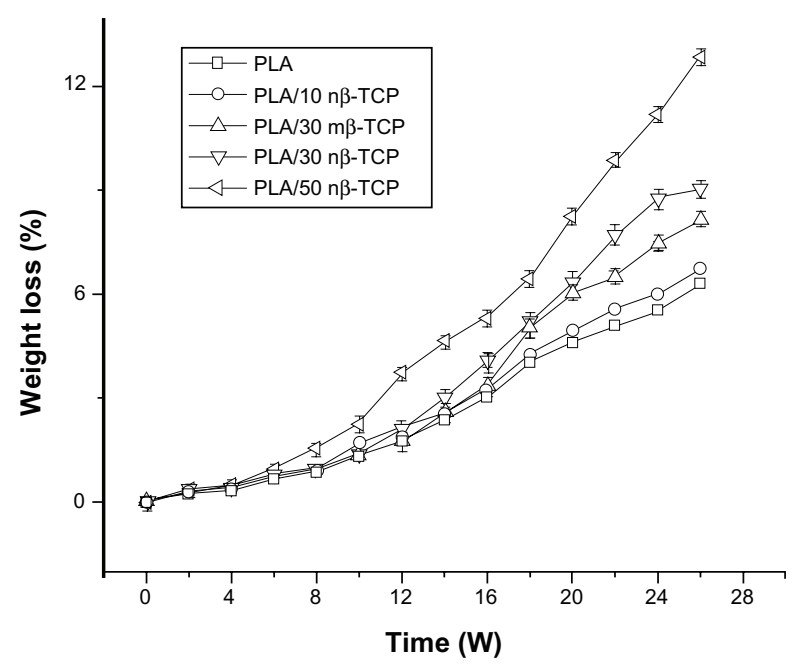

Figure 5 Weight loss of porous scaffolds with different initial ratios of $n \beta-T C P$. Abbreviations: PLA, poly (lactic acid); $n \beta-T C P$, nano-sized $\beta$-tricalcium phosphate; m $\beta$-TCP, micro-sized $\beta$-tricalcium phosphate; $W$, weeks. 


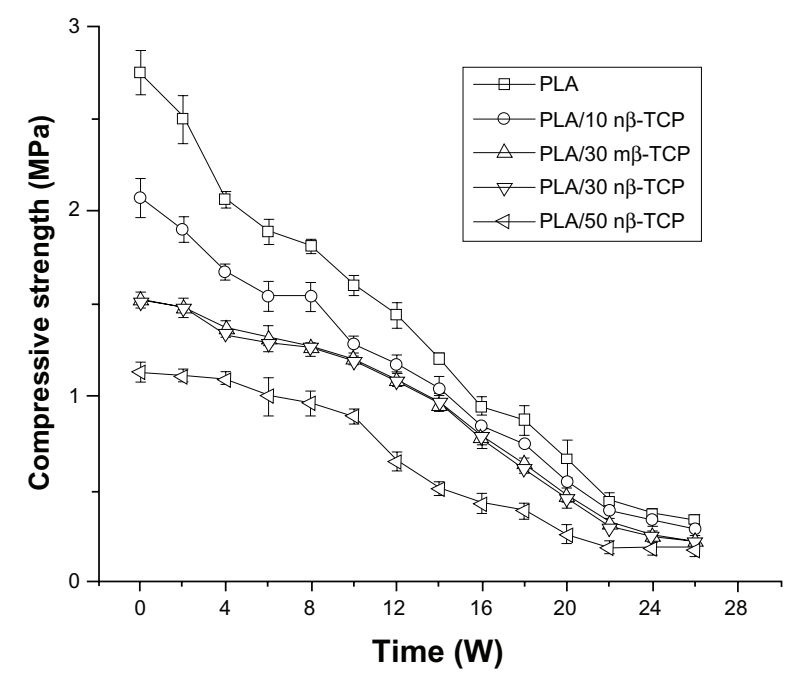

Figure 6 Changes in compressive strength of porous scaffolds with different initial ratios of $n \beta$-TCP.

Abbreviations: PLA, poly (lactic acid); $\mathrm{n} \beta$-TCP, nano-sized $\beta$-tricalcium phosphate; $\mathrm{m} \beta$-TCP, micro-sized $\beta$-tricalcium phosphate; $W$, weeks.

regard to new bone formation was found between PLA/30 $n \beta-T C P$ and PLA $/ 50$ n $\beta$-TCP (33.2\% $\pm 1.5 \%)$ (Figure 9).

\section{Immunohistochemistry}

In OCN-positive tissue, immunostaining could be identified in osteocytes, and the staining was predominantly localized in the nucleus (Figure 8). Among the five groups, PLA/50 n $\beta$-TCP, PLA/30 n $\beta$-TCP, and PLA/30 m $\beta$-TCP showed strong staining of OCN, whereas PLA/10 n $\beta$-TCP and PLA scaffolds exhibited moderate and weak staining, respectively.

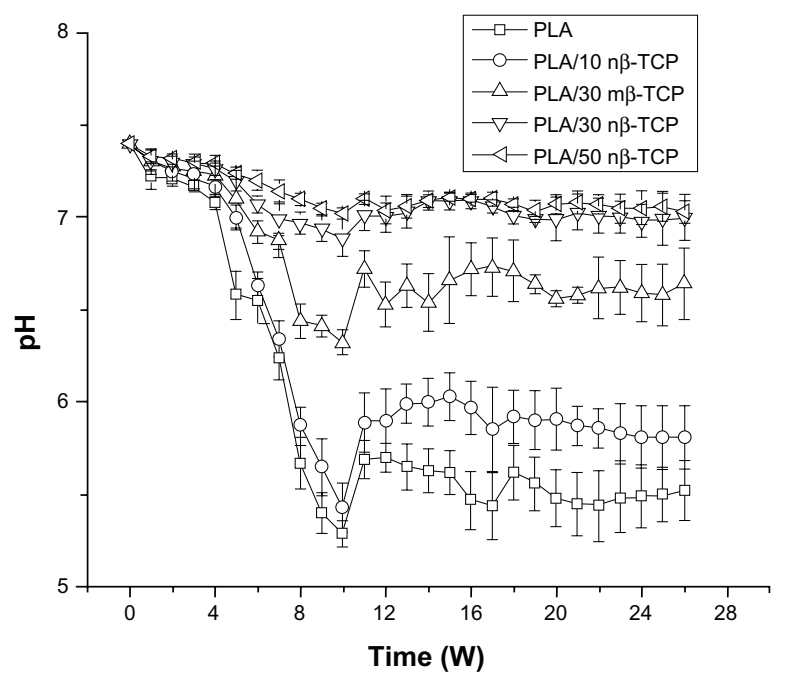

Figure 7 Changes in $\mathrm{pH}$ of PBS solution used for in vitro degradation of composite scaffolds at $37^{\circ} \mathrm{C}$.

Abbreviations: PBS, phosphate-buffered saline; PLA, poly (lactic acid); $n \beta-T C P$, nano-sized $\beta$-tricalcium phosphate; $\mathrm{m} \beta$-TCP, micro-sized $\beta$-tricalcium phosphate; $W$, weeks.

\section{Discussion}

The present study investigated in vitro degradation behaviors of the PLA/n $\beta$-TCP composite scaffolds by determining changes in $\mathrm{pH}$, weight, compressive strength, porosity, and microstructure in PBS at $\mathrm{pH} 7.4$ and $37^{\circ} \mathrm{C}$ over 26 weeks. We also studied the osteoconductivity of the PLA/n $\beta$-TCP composite scaffolds by assessing ectopic bone formation in back muscle pouches of rabbits in the presence of rhBMP-2.

The acidic degradation products of PLA lead to a decrease in $\mathrm{pH}$, which may cause cell morphological changes and eventually lead to cell death. ${ }^{18} \beta$-TCP has been employed as a filler in order to improve osteoconductivity and to offset acid degradation products of PLA scaffolds. ${ }^{19-22}$ The ratio of $\beta$-TCP in the scaffold composite strongly influences its degradation properties. It remains controversial whether $\beta$-TCP can buffer acid products. Haaparanta et $\mathrm{al}^{23}$ fabricated PLA/ $\beta$-TCP scaffolds using a similar method to ours: they studied composite scaffolds containing 5, 10, and $20 \mathrm{wt} \%$ of $\mathrm{m} \beta$-TCP, and they reported that there was no significant buffering effect of $\beta$-TCP on the $\mathrm{pH}$ of the degradation medium in all groups. However, many studies, including the present study, have shown a $\mathrm{pH}$ buffering effect of $\beta$-TCP in PLA composite materials. ${ }^{24,25}$ The $\beta$-TCP ratio and particle size may be the main reasons for the conflicting results. We compared the change of $\mathrm{pH}$ between scaffolds containing $30 \mathrm{wt} \% \mathrm{~m} \beta$-TCP and $30 \mathrm{wt} \% \mathrm{n} \beta$-TCP: the results indicated that the buffering effect of $n \beta-\mathrm{TCP}$ was stronger than that of $\mathrm{m} \beta$-TCP. We also studied the effect of different content of $n \beta-T C P$ on $\mathrm{pH}$ change: decreased $\mathrm{pH}$ was detected in the PLA/10 n $\beta$-TCP and pure PLA groups, while an obvious and consistent $\mathrm{pH}$ buffering effect was observed after 4 weeks when the content of $\mathrm{n} \beta$-TCP was $30 \%$ or $50 \%$ of total weight, indicating an evident dependence on the TCP ratio.

In addition to the effect of degradation products on the microenvironment, an appropriate 3-D structure (pore size and porosity) that facilitates cell attachment, proliferation, as well as the transport of nutrients and metabolic waste is a crucial factor for bone regeneration. ${ }^{26}$ It is generally acknowledged that higher porosity and larger pore size result in better in vivo bone ingrowth, ${ }^{27}$ and that porosity about $70 \%$, pore size of $100-500 \mu \mathrm{m}$, and mechanical strength similar to natural bone are ideal scaffold characteristics. ${ }^{28}$ All the scaffolds in the present study exhibited appropriate physical structures with volume porosities higher than $70 \%$ and pore diameters of 150-350 $\mu \mathrm{m}$. However, due to processing of the scaffold by freeze-drying, $50 \mathrm{wt} \%$ filler content was shown to be the upper limit to obtain a homogeneous and interconnected cellular architecture. In addition, increasing $\beta$-TCP content 


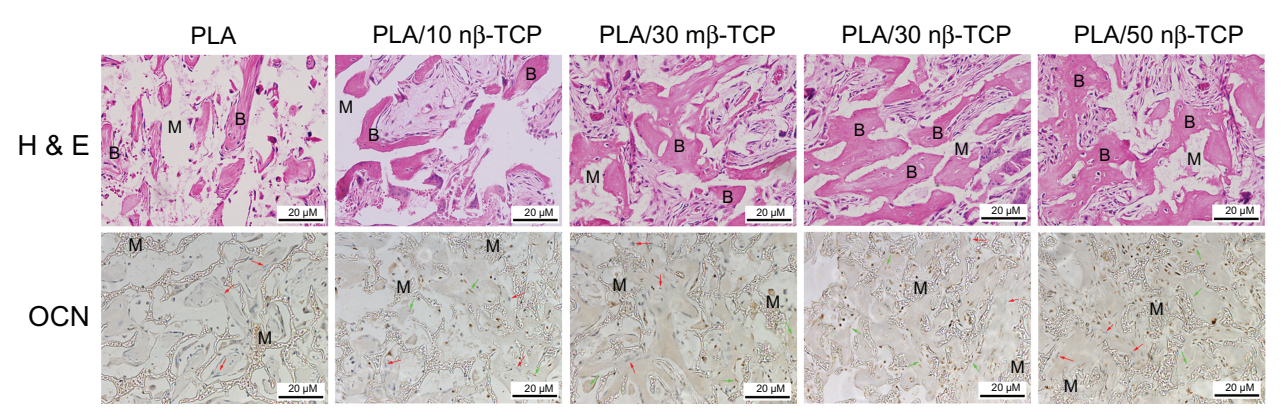

Figure $8 \mathrm{H} \& \mathrm{E}$ and OCN immunohistochemistry stain at 8 weeks demonstrating new bone and materials in each of the five groups: pure PLA, PLA/I0 $n \beta-T C P, P L A / 30$ m $\beta$ TCP, PLA/30 n $\beta$-TCP, and PLA/50 n $\beta$-TCP scaffolds.

Notes: $B$ indicates new bone. $M$ indicates materials. Green arrow indicates OCN-positive cells, red arrow indicates negative cells. Scale bars: $20 \mu \mathrm{m}$.

Abbreviations: H\&E, hematoxylin and eosin; OCN, anti-osteocalcin; PLA, poly (lactic acid); $n \beta$-TCP, nano-sized $\beta$-tricalcium phosphate; $\mathrm{m} \beta$-TCP, micro-sized $\beta$-tricalcium phosphate.

makes the composite material brittle and thus, less resistant to deformation. ${ }^{29}$ Our results showed that PLA/30 n $\beta$-TCP and PLA/10 n $\beta$-TCP scaffolds exhibited better mechanical properties than PLA/50 n $\beta$-TCP scaffolds.

Previous studies have indicated that the incorporation of $\beta$-TCP into PLA scaffolds enhances osteoinductivity. This effect has been specifically highlighted in a rabbit model, ${ }^{30}$ which established a clear correlation between bone healing and the content of $\beta$-TCP particles mixed with PLA at $60^{\circ} \mathrm{C} \pm 5^{\circ} \mathrm{C}$ in air, and showed a 50/50 PLA/ $\beta$-TCP ratio exhibiting the best results. However, bone was considered as a nanocomposite material, and nanoparticles had better bioactivity and osteoconductivity than microparticles. Our histological result indicated that the composite scaffolds containing $n \beta$-TCP had bigger bone areas than scaffolds containing $\mathrm{m} \beta$-TCP.

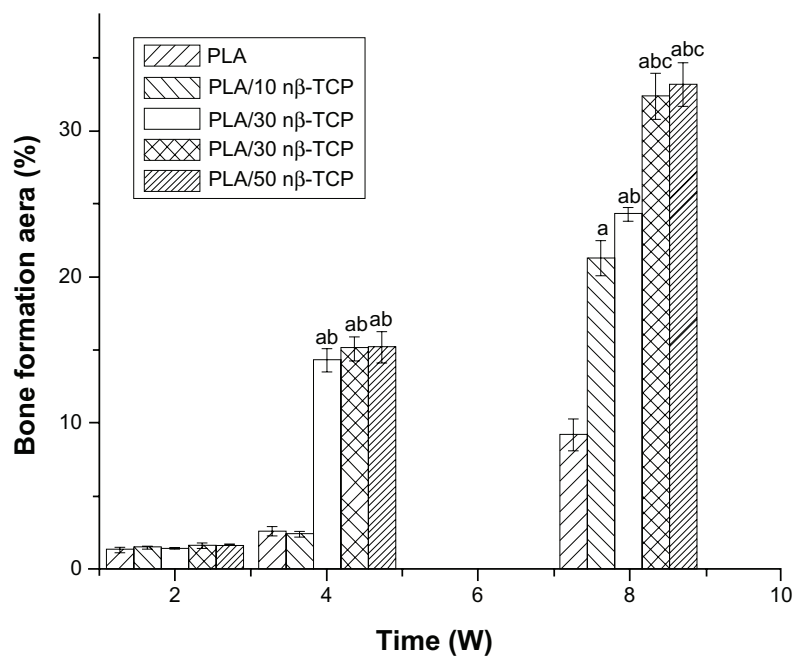

Figure 9 Graph of neo-bone area from rhBMP-2 loaded scaffolds at 2, 4, and 8 weeks.

Notes: Significance compared to pure PLA (a), PLA/I0 n $\beta$-TCP (b), PLA/30 m $\beta$ TCP (c), PLA/30 n $\beta$-TCP (d), PLA/50 n $\beta$-TCP scaffolds (e).

Abbreviations: rhBMP-2, recombinant human bone morphogenetic protein-2; OCN, anti-osteocalcin; PLA, poly (lactic acid); $n \beta-T C P$, nano-sized $\beta$-tricalcium phosphate; $\mathrm{m} \beta$-TCP, micro-sized $\beta$-tricalcium phosphate.
The various contents of $n \beta$-TCP also resulted in differences of osteoconductivity. The in vivo results demonstrated that both of the scaffolds containing 30\% and 50\% n $\beta$-TCP exhibited enhanced ingrowth of new bone, and had similar biological performance in terms of osteogenesis. In accordance with the in vitro degradation results, both PLA/30 $\mathrm{n} \beta$-TCP and PLA/50 n $\beta$-TCP scaffolds maintained the PBS $\mathrm{pH}$ level during the degradation period. For comparison, $\mathrm{pH} 7.2$ was considered as optimal for osteoblasts. ${ }^{31}$ The $\mathrm{pH}$ buffering effect was not detected in the PLA/10 n $\beta$-TCP and pure PLA scaffold, in agreement with the weak osteoconductivity of this scaffold.

\section{Conclusion}

The degradation behaviors and osteogenic potentials of porous $\mathrm{PLA} / \mathrm{n} \beta$-TCP scaffolds were investigated under in vitro and in vivo conditions. The results showed that the $n \beta$-TCP content did not markedly affect the microstructure of the composite scaffolds, but significantly influenced the in vitro degradation and in vivo osteoconductive properties. The buffering effect of $n \beta$-TCP was confirmed in the present study, and this effect appears to be directly related to the $n \beta$-TCP ratio. PLA/30 $\mathrm{n} \beta$-TCP scaffolds exhibited similar osteogenesis as compared to PLA/50 n $\beta$-TCP, but the PLA/50 n $\beta$-TCP scaffold was too brittle to be used in bone repair. In contrast, PLA/30 n $\beta$-TCP scaffolds may have potential applications due to their outstanding mechanical properties that can meet the requirements of bone repair in load-bearing sites.

\section{Acknowledgments}

This work was supported by the National Basic Research Program of China (973 program) (2009CB930002), Shanghai International Science and Technology Partnership Program (11540702700), Natural Science Foundation of China 
(31170925), and the National Natural Science Foundation of China (30970718).

\section{Disclosure}

The authors report no conflicts of interest in this work.

\section{References}

1. Chan BP, Leong KW. Scaffolding in tissue engineering: general approaches and tissue specific considerations. Eur Spine J. 2008; 17 Suppl 4:467-479.

2. Schofer MD, Roessler PP, Schaefer J, et al. Electrospun PLLA nanofiber scaffolds and their use in combination with BMP-2 for reconstruction of bone defects. PLoS One. 2011;6(9):e25462.

3. Martínez-Vázquez FJ, Perera FH, Miranda P, Pajares A, Guiberteau F. Improving the compressive strength of bioceramic robocast scaffolds by polymer infiltration. Acta Biomater. 2010;6(11):4361-4368.

4. Wang J, Qu L, Meng X, Gao J, Li H, Wen G. Preparation and biological properties of PLLA/beta-TCP composites reinforced by chitosan fibers. Biomed Mater. 2008;3(2):025004.

5. Crouzier T, Sailhan F, Becquart P, Guillot R, Logeart-Avramoglou D, Picart C. The performance of BMP-2 loaded TCP/HAP porous ceramics with a polyelectrolyte multilayer film coating. Biomaterials. 2011; 32(30):7543-7554.

6. Kasuga T, Maeda H, Kato K, Nogami M, Hata K, Ueda M. Preparation of poly(lactic acid) composites containing calcium carbonate (vaterite). Biomaterials. 2003;24(19):3247-3253.

7. Georgiou G, Mathieu L, Pioletti DP, et al. Polylactic acid-phosphate glass composite foams as scaffolds for bone tissue engineering. J Biomed Mater Res B Appl Biomater. 2007;80(2):322-331.

8. Ye X, Chen M, Yang M, Wei J, Liu D. In vitro corrosion resistance and cytocompatibility of nano-hydroxyapatite reinforced $\mathrm{Mg}-\mathrm{Zn}-\mathrm{Zr}$ composites. J Mater Sci Mater Med. 2010;21(4):1321-1328.

9. Lin K, Chang J, Shen R. The effect of powde ${ }_{r}$ properties on sintering, microstructure, mechanical strength and degradability of beta-tricalcium phosphate/calcium silicate composite bioceramics. Biomed Mater. 2009;4(6):065009.

10. Price RL, Ellison K, Haberstroh KM, Webster TJ. Nanometer surface roughness increases select osteoblast adhesion on carbon nanofiber compacts. J Biomed Mater Res A. 2004;70(1):129-138.

11. Washburn NR, Yamada KM, Simon CJ, Kennedy SB, Amis EJ. Highthroughput investigation of osteoblast response to polymer crystallinity: influence of nanometer-scale roughness on proliferation. Biomaterials. 2004;25(7-8):1215-1224

12. Wan Y, Wang Y, Liu Z, et al. Adhesion and proliferation of OCT-1 osteoblast-like cells on micro- and nano-scale topography structured poly(L-lactide). Biomaterials. 2005;26(21):4453-4459.

13. So K, Takemoto M, Fujibayashi S, Neo M, Kokubo T, Nakamura T. Reinforcement of tendon attachment to bioactive porous titanium by BMP-2-induced ectopic bone formation. J Biomed Mater Res A. 2010;93(4):1410-1416.

14. Haimi S, Suuriniemi N, Haaparanta AM, et al. Growth and osteogenic differentiation of adipose stem cells on PLA/bioactive glass and PLA/ beta-TCP scaffolds. Tissue Eng Part A. 2009;15(7):1473-1480.
15. Wu L, Ding J. In vitro degradation of three-dimensional porous poly(D,L-lactide-co-glycolide) scaffolds for tissue engineering. Biomaterials. 2004;25(27):5821-5830.

16. Zhang R, Ma PX. Poly(alpha-hydroxyl acids)/hydroxyapatite porous composites for bone-tissue engineering. I. Preparation and morphology. J Biomed Mater Res. 1999;44(4):446-455.

17. Becker ST, Bolte H, Krapf O, et al. Endocultivation: 3D printed customized porous scaffolds for heterotopic bone induction. Oral Oncol. 2009;45(11):e181-e188.

18. Kang Y, Yao Y, Yin G, et al. A study on the in vitro degradation properties of poly(L-lactic acid)/beta-tricalcuim phosphate (PLLA/ beta-TCP) scaffold under dynamic loading. Med Eng Phys. 2009;31(5): 589-594.

19. Debusscher F, Aunoble S, Alsawad Y, Clement D, Le Huec JC. Anterior cervical fusion with a bio-resorbable composite cage (beta TCP-PLLA): clinical and radiological results from a prospective study on 20 patients. Eur Spine J. 2009;18(9):1314-1320.

20. Barber FA, Boothby MH. Bilok interference screws for anterior cruciate ligament reconstruction: clinical and radiographic outcomes. Arthroscopy. 2007;23(5):476-481.

21. Barber FA, Dockery WD. Long-term absorption of beta-tricalcium phosphate poly-L-lactic acid interference screws. Arthroscopy. 2008;24(4): $441-447$.

22. Huang J, Zhang L, Chu B, Peng X, Tang S. Repair of bone defect in caprine tibia using a laminated scaffold with bone marrow stromal cells loaded poly (L-lactic acid)/beta-tricalcium phosphate. Artif Organs. 2011;35(1):49-57.

23. Haaparanta AM, Haimi S, Ellä V, et al. Porous polylactide/betatricalcium phosphate composite scaffolds for tissue engineering applications. J Tissue Eng Regen Med. 2010;4(5):366-373.

24. Yang F, Cui WJ, Xiong Z, Liu L, Bei JZ, Wang SG. Poly(L,L-lactideco-glycolide)/tricalcium phosphate composite scaffold and its various changes during degradation in vitro. Polym Degrad Stab. 2006;91(12): 3065-3073.

25. Huttunen M, Ashammakhi N, Törmälä P, Kellomäki M. Fibre reinforced bioresorbable composites for spinal surgery. Acta Biomater. 2006;2(5): $575-587$.

26. Tu J, Wang H, Li H, Dai K, Wang J, Zhang X. The in vivo bone formation by mesenchymal stem cells in zein scaffolds. Biomaterials. 2009;30(26):4369-4376.

27. Karageorgiou V, Kaplan D. Porosity of 3D biomaterial scaffolds and osteogenesis. Biomaterials. 2005;26(27):5474-5491.

28. de Barros Coelho M, Magalhães Pereira M. Sol-gel synthesis of bioactive glass scaffolds for tissue engineering: effect of surfactant type and concentration. J Biomed Mater Res B Appl Biomater. 2005;75(2): 451-456.

29. van der Pol U, Mathieu L, Zeiter S, et al. Augmentation of bone defect healing using a new biocomposite scaffold: an in vivo study in sheep. Acta Biomater. 2010;6(9):3755-3762.

30. Aunoble S, Clément D, Frayssinet P, Harmand MF, Le Huec JC. Biological performance of a new beta-TCP/PLLA composite material for applications in spine surgery: in vitro and in vivo studies. $J$ Biomed Mater Res A. 2006;78(2):416-422.

31. Kaysinger KK, Ramp WK. Extracellular $\mathrm{pH}$ modulates the activity of cultured human osteoblasts. J Cell Biochem. 1998;68(1):83-89.

International Journal of Nanomedicine

\section{Publish your work in this journal}

The International Journal of Nanomedicine is an international, peerreviewed journal focusing on the application of nanotechnology in diagnostics, therapeutics, and drug delivery systems throughout the biomedical field. This journal is indexed on PubMed Central, MedLine, CAS, SciSearch $\AA$, Current Contents $₫ /$ Clinical Medicine,

Journal Citation Reports/Science Edition, EMBase, Scopus and the Elsevier Bibliographic databases. The manuscript management system is completely online and includes a very quick and fair peer-review system, which is all easy to use. Visit http://www.dovepress.com/ testimonials.php to read real quotes from published authors. 